\title{
Exploring Business Strategy Modelling with ArchiMate: A Case Study Approach
}

\author{
Fotis Kitsios *(D), Maria Kyriakopoulou and Maria Kamariotou
}

Citation: Kitsios, F.; Kyriakopoulou, M.; Kamariotou, M. Exploring Business Strategy Modelling with ArchiMate: A Case Study Approach. Information 2022, 13, 31. https:// doi.org/10.3390/info13010031

Academic Editor: Rúben Pereira

Received: 28 November 2021

Accepted: 10 January 2022

Published: 12 January 2022

Publisher's Note: MDPI stays neutral with regard to jurisdictional claims in published maps and institutional affiliations.

Copyright: () 2022 by the authors Licensee MDPI, Basel, Switzerland. This article is an open access article distributed under the terms and conditions of the Creative Commons Attribution (CC BY) license (https:/ / creativecommons.org/licenses/by/ $4.0 /)$.

\author{
Department of Applied Informatics, University of Macedonia, GR54636 Thessaloniki, Greece; \\ dai16068@uom.edu.gr (M.K.); mkamariotou@uom.edu.gr (M.K.) \\ * Correspondence: kitsios@uom.gr
}

\begin{abstract}
Enterprise architecture (EA) is a high-level abstraction of a business' levels that aids in organizing planning and making better decisions. Researchers have concluded that the scope of EA is not focused only on technology planning but that the lack of business strategy and processes is the most important challenge of EA frameworks. The purpose of this article is to visualize the business strategy of a company using ArchiMate. Having a better understanding of how the concepts of strategic planning are used in businesses, we hope to improve their modelling with ArchiMate. This article adds to the existing literature by evaluating existing EA modelling languages and their skillfulness in model strategy. Furthermore, this article contributes to the identification of challenges in modelling and investigation of the ease of the use of language in the field of strategic planning. Furthermore, this article provides an approach to practitioners and EA architects who are attempting to develop efficient EA modelling projects and solve business complexity problems.
\end{abstract}

Keywords: business strategy; strategic planning process; enterprise architecture; modelling; ArchiMate

\section{Introduction \\ 1.1. Problem Statement}

Companies use enterprise architecture (EA) to provide an integrated environment and support the integration of business and IT strategy [1-4]. The alignment between business strategy with IT is a significant management concern [5] that supports managers in achieving business goals, improving work-flow, increasing profitability, and sustaining a competitive advantage [5-9]. EA is a structured and aligned set of plans for the integrated representation of a given business and IT landscape in past, present, and future situations. It is a comprehensive tool for managing and retaining alignment $[10,11]$. Many academics argue that combining business strategy with EA helps achieve competitiveness and value, reduce the organization uncertainty, and maximize agility, company's availability, and fault tolerance [12-14]. Besides, many researchers have concluded that the business strategy has not been fully integrated with EA frameworks [12-14].

The implementation of a business strategy is a significant aspect of organizational success. However, the understanding of a holistic perspective should facilitate the strategy formulation and visualization of related processes [15]. EA academics have also focused on modelling business strategy [16-19]. However, until now, the implementation of the business strategy through EA has been poorly understood and practitioners have regarded it as a difficult problem [15].

Academics conclude that this is required to represent how concepts in a company's architecture are related to its business strategy or how changes to the architecture may ensure a formulated business strategy. Moreover, practitioners can define how to model business strategy, as well as how it affects EA. This assists businesses in analyzing and determining which function is best aligned with the strategic intent (scale, money, and time) [16-21]. 
It would appear that more studies are required, in order to achieve methodological consistency and integration [10]. As scholars conclude that strategic planning into EA can improve the traceability between an organization's strategic planning and EA choices and EA can also be used for strategy formulation, the modelling of business strategy in EA is a significant step towards this alignment. Without being able to envision what that process looks like, it becomes difficult to fully comprehend what is required for success. Therefore, scholars suggest more practical case studies should be conducted, in order to improve the ease of use and clarity of business strategy concepts.

SMEs need to (re-)consider revitalizing their strategies, involving crisis scenarios and business continuity plans, using alternative or additional distribution channels to increase their revenues. Practically, retaining consumers virtually is a complicated process, since it would irreversibly hurt businesses by delivering a low-quality service. Due to the various difficulties and uncertainties faced by organizations during COVID-19, multiple scenarios for future strategic actions must be established by organizational actors.

In this new environment, SMEs face many challenges, due to a lack of technical, organizational, and human resources. Due to a lack of strategic planning, alignment between organizational and IT goals, and formal processes, SMEs develop ineffective IT projects [22-27]. IT executives try to achieve a high level of alignment between IT and organizational structure to develop services that support business goals and increase the business value $[28,29]$. Managers should be knowledgeable about business strategy, in order to help with the development of IT projects [30,31].

\subsection{Purpose and Contribution}

The purpose of this article is to visualize the "As-Is" business strategy of a company using ArchiMate. The ArchiMate modelling language was chosen as the basis for this paper because it includes a series of strategy elements that can be used by enterprise architects to model strategic planning in their firms. The goal was to ensure a better understanding of how business strategy and EA can be combined to impose more structure in an organization's strategic planning process, taking into account all of the required steps that are necessary to formulate a business strategy.

This paper may be of interest to researchers who have been introduced to the field but are interested in examining more specific insights into where current research topics in business strategy can be located and how they may contribute to them. Within the rapidly changing business environment, managers have focused on strategic planning in gaining competitive advantage. In contrast to existing studies, which modelled some concepts of business strategy in large organizations, this paper may be used as a tool that allows executives to become aware of business strategy concepts that need to be considered when trying to develop successful SMEs.

The modelling of business strategy assists SMEs in aligning with business operations and organizational processes, in order to better understand their organizational vision, mission, goals, and culture, as well as to gain a competitive advantage. In contrast to previous studies that present business strategy modelling in organizations, in this paper we present the modelling of business strategy in a small-medium enterprise to highlight the extent of alignment between business processes and strategy. Thus, managers, through the visualization of the company's strategy, should be aware of its strategy, organizational goals, and structure to effectively use the company's resources and develop digital tools that help the organization digitalize its processes and increase its competitive advantage.

The specific company tries to digitalize its processes, in order to communicate with their customers to learn about their needs and develop more qualitative products. The company is constantly striving to evolve and integrate technology into its product line to achieve more outstanding quality and success, while saving money and resources during the manufacturing process. Furthermore, technology has evolved into a powerful media, with the Internet serving as a source of information for new market trends and 
developments in all business activities. Finally, the company utilizes technology to generate online sales and participate in this new market trend.

The reminder of the paper has been structured as follows. The following section presents studies related to EA and business strategy. The third section describes the methodology used to visualize business strategy using ArchiMate. Then, in the following sections, the modelling results are discussed. Finally, conclusions and future research suggestions are provided.

\section{Literature Review}

\subsection{Modelling Business Strategy}

This section presents a theoretical background to the main concepts of business strategy, as well as the findings of previous surveys that have modelled business strategy concepts using the ArchiMate language. The goal of this section is to provide an understanding of how these concepts can be modelled using ArchiMate, as well as to present current state-of-the-art research in this field.

Strategic planning is one of the most popular management tools in contemporary companies. Academics highlight that strategic planning plays a vital role in strategy development, incorporating how companies formulate significant problems, identifying goals, analyzing alternatives, and choosing a strategy [32-35].

The fundamental steps of the strategic planning process are strategy analysis, formulation, and implementation. The first step in strategic planning is the identification of the vision. The vision represents the desired future state of businesses. The mission describes the activities of a company and what it does on a daily basis. It involves all business strategies and makes the vision operative. Thus, "mission" describes a company's processes that enable the vision to be realized [36].

A business strategy is identified as a plan for the future situation of a business. According to another definition, "business strategy" refers to the activities that a company intends to undertake and how it intends to act, in order to align its vision with a sustainable competitive advantage $[16,17]$. Other scholars have identified business strategy as an understanding of an industry's structure and dynamics, determining the business's relative position in that industry, and intending to change the industry's structure or the business's position, in order to improve business results [36,37]. A business strategy can be considered as a plan or action that a company takes to achieve its goals. In other words, a business strategy presents an understanding of a company's resources, situation, and relationship with the environment. A business strategy should define, protect, acquire, and sustain critical capabilities [19]. The business strategy determines, in terms of strategic objectives, resources, competencies, and capabilities, where the businesses intend to be in the future [38].

After determining the strategy, the executives translated it into specific, measurable goals. As a result, they refer to statements of specific outcomes that must be achieved and are usually performance measures, specific objectives that must be managed, and initiatives that can be implemented to achieve them $[16,38]$. The balanced scorecard (BSC) is a method that helps measure goals. The BSC assesses the extent to which objectives are met from the following perspectives: financial, customer, business process, and development $[15,39-44]$.

A strategy map includes details about the mission, core values, vision, and strategies that are aligned and increases organizational performance. The starting point of a strategy map is defining the mission statement and core values. A strategic vision is required, based on mission and core values. The next step is to consider the financial perspective, which includes evaluating the cost structure and expansion of revenue opportunities. Then, from the customer's perspective, it involves the value proposition. This point of view is aligned with product or service characteristics, such as brand, price, quality, partnership, availability, functionality, and service. The internal perspective describes the operations management, innovation, customer management, and social processes for the value proposition. Finally, 
in terms of learning and growth, human capital is combined with organizational and information capital [18,42,45].

Executives make decisions about formulating a strategy based on the analysis of the external and internal environment and definition of the factors that affect the company. Strengths, weaknesses, opportunities, and threats (SWOT) is a well-known categorization of factors. A significant question about strategic planning is how companies achieve and sustain a competitive advantage. Executives analyze the internal environment using value chain analysis. The strategy presents how this value can be developed. The value network is a comprehensive view of the value chain. Two points of view make a significant difference. The value chain concentrates on the business itself or the industry. Otherwise, the value network focuses on the value-creating system, in which several actors create value $[17,18]$.

Significant challenges are addressed, including "How do companies create value for customers?", "How can companies convert added value into profit?", "How do companies organize value delivery and how can they develop sustainable cost advantages?", and "How do companies attract and retain customers?". Companies deal with these challenges to develop business models to increase business value [46-49]. However, just developing IT is not enough. Business processes and IT should be aligned with strategy, in order to increase business value, performance, and competitive advantage [50,51].

In the field of strategic planning, many researches have conducted case studies, in order to visualize only specific aspects of business strategy using ArchiMate. However, existing articles conclude that more case studies are required to understand how the whole business strategy can be modelled based on primary data [20]. Lee and Song (2011) [52] carried out a case study in healthcare facilities and used a goal-oriented approach to visualize a firm's strategy, top goals, and sub goals in the health sector. They examined business services and other aspects of the business layer, in order to optimize business processes and functions and understand the linked aspects of the business layer. In the same sector, Girsang et al. (2021) [53] modelled business strategy using TOGAF ADM and tried to solve the lack of alignment between business strategy and IT strategy, lack of awareness of using IT as a tool for competitive advantage, and low quality of IT operation performances. As there is still no alignment between business strategy and IT assets, it is necessary to implement EA, in order to have appropriateness between the organizational goal and strategy's execution in the field. As a result, many researchers from various fields devised novel approaches to modelling business-IT alignment using the TOGAF ADM method [54-56].

Iacob et al. (2012) [38] investigated the suitability of the ArchiMate EA modelling language to support the modelling of strategic planning concepts and architecture-based approaches to IT portfolio valuation. Their process was also illustrated using an application portfolio consolidation case study. The authors demonstrated how a constrained optimization valuation method could be implemented into architecture models enhanced with the new elements. According to this point of view, Aldea et al. (2015) [16] investigated whether the ArchiMate modelling language can be used to visualize the widely used strategy elements and theories. The authors identified the meanings of various concepts involved in strategic management. Then they visualized them with ArchiMate, using an example of an anonymized case of a healthcare organization. Aldea et al. (2013) [18] used ArchiMate to create a visualisation of an insurance company's strategic goals. They examined the strategic planning process in this company and attempted to align particular goals and strategies with comprehending how specific strategic choices can influence the organization's architecture.

In contrast, Azevedo et al. (2015) [43] developed an ontological analysis using ArchiMate to visualize resources and capabilities. The authors used two case studies (an automotive company and energy supplier company) to demonstrate the semantics of the suggested modelling constructs, which should aid in the practical application of the language. Danesh and $\mathrm{Yu}(2018)$ and Danesh and $\mathrm{Yu}(2014)[57,58]$ presented a different approach to model capabilities. They used the $\mathrm{i}^{*}$ language to model capabilities as a specialized intentional 
actor, so that their socio-technical characteristics could be specified and analyzed. This approach to modeling capabilities enables reasoning about why a capability is needed, how it is achieved, how it fits within the organizational and social setting of the enterprise, and what relationships are required for its success. Aldea et al. (2018) [19] developed a management dashboard tool, based on the principles of ArchiMate, to visualize different strategic concepts and business canvases in many case studies. They concentrated on SWOT analysis, the balanced scorecard method, goal setting, and resource and capability analysis.

Other researchers focused on visualizing value and how value can be delivered to customers. For example, Iacob et al. (2012) [38] visualized the business model of an insurance company, using ArchiMate to explore the relationship between business value creation and enterprise architecture. They pay attention to the connection of business models with the IT infrastructure level, through the use of ArchiMate to model them. They tried to ensure a smooth transition from operational architecture descriptions to strategic business models with motivation and resource-capability models. Aldea et al. (2015) [17] using ArchiMate, visualized the value chain of an insurance company. They proposed a framework for visualizing value and related concepts with ArchiMate. Sandkuhl et al. (2020) [59] focused on visualization of service or product value using the 4EM method. Furthermore, Sandkuhl et al. (2014) [60] presented and compared various enterprise modelling focus areas (for example, active knowledge modeling, C3S3P, 4EM, ArchiMate, ARIS, DEMO, MEMO, and OMI) to present the visualization of concepts, such as products, services, and resources. Finally, Kitsios et al. (2020) [48] used ArchiMate to visualize the business model of the open data ecosystem in Greece, with the view of discussing the relationships between the actors of open data network, as well as the business model aspects required to sustain the activities of these entities in the open data-based business. They identified the ecosystem's actors, roles and activities, primary customer relationships, and resources needed to produce value while minimizing costs. These concepts were demonstrated using the business model canvas before being visualized with ArchiMate by the authors. Finally, Caetano et al. (2015) [61] described an implementation of ontologies for the representation, integration, and analysis of enterprise models and applied it to the integrated analysis of three enterprise modelling languages: the business model canvas, e3value, and ArchiMate.

\subsection{ArchiMate}

ArchiMate is a modelling language that The Open Group developed. ArchiMate is an open and independent architecture modelling language. It includes business processes, information flows, organizational structures, information systems, and technical infrastructure. The ArchiMate language is divided into layers that combine business processes with infrastructure. The significant elements of the business layer are the products and services that are offered to consumers. The application layer supports the business with application services that any application can accomplish. The technology layer includes infrastructure services for processing, data storage, and communication. They must develop applications, computer and communication hardware, and system software [16,17,38,52,62,63].

The latest version of ArchiMate 3.1 was used [64]. Table 1 summarizes the main concepts suggested in the literature to model business strategy and how they can be used in ArchiMate.

Aldea et al. (2015) [16,17] also suggested the way that these concepts, regarding business strategy, relate to each other by using standard ArchiMate relationships to model business strategy with this language. Table 2 shows the relationships between ArchiMate's business strategy concepts. 
Table 1. Summary of the basic concepts of strategic management in ArchiMate.

\begin{tabular}{|c|c|c|}
\hline Concept & Definition & References \\
\hline Goal & $\begin{array}{l}\text { It represents some aims that a stakeholder wants to } \\
\text { accomplish }\end{array}$ & {$[38,52,63]$} \\
\hline Capability & The ability to employ resources to achieve some goals & {$[38,39,43]$} \\
\hline Stakeholder & $\begin{array}{l}\text { It refers to a person or a group who has an interest or } \\
\text { concern about the outcome of the architecture }\end{array}$ & {$[16,17,38]$} \\
\hline Mission & $\begin{array}{l}\text { What organisations are doing or intend to do on a daily } \\
\text { basis }\end{array}$ & {$[16,17,38]$} \\
\hline Vision & High-level goal & {$[16,17,38]$} \\
\hline Strategy & $\begin{array}{l}\text { It is used to describe a plan for the future and could be } \\
\text { identified as a goal that needs to be fullfilled, in order to } \\
\text { manage the vision of an organization }\end{array}$ & {$[16,17]$} \\
\hline Objective & It is a statement of specific outcomes that are to be achieved & {$[16,17,38]$} \\
\hline Driver & $\begin{array}{l}\text { It represents an internal or external factor that triggers and } \\
\text { motivates change in a company }\end{array}$ & {$[16,17,38]$} \\
\hline Assessment & It represents the outcome of a particular analysis of a driver & {$[16,17,38]$} \\
\hline Requirement & $\begin{array}{l}\text { It is used to describe what is required to be able to achieve a } \\
\text { particular goal }\end{array}$ & {$[16,17,38]$} \\
\hline Constraint & It describes restrictions on the way a goal can be achieved & {$[16,17,38]$} \\
\hline Principle & It is used to represent a method of achieving a goal & {$[16,17,38]$} \\
\hline
\end{tabular}

Table 2. Relationships between concepts.

\begin{tabular}{ccc}
\hline Concept $\mathbf{1}$ & Concept 2 & ArchiMate Relationship Meaning \\
\hline Mission & Vision & Influence \\
Strategy & Mission & Influence \\
Assessment & Driver & Association \\
Assessment & Goal & Association \\
Resource & Driver & Association \\
Resource & Capability & Used by \\
Capability & Driver & Association \\
Driver & Stakeholder & Association \\
Driver & Goal & Association \\
Objective & Strategy & Influence \\
Objective & Objective & Influence \\
Stakeholder & Goal & Association \\
\hline
\end{tabular}

Each of the following levels is visualized by the ArchiMate: business, application, and infrastructure. This contributes to the alignment of the strategic business vision and IT. In addition, based on the integration between the three layers, there is also the possibility of aligning the strategic layer with the operation one. This perspective increases the likelihood of having a top-down and bottom-up view on EA. Furthermore, the integration of business and IT aspects helps align a business strategy with the IT infrastructure $[65,66]$.

The use of ArchiMate has two benefits. ArchiMate describes the impact of new strategies on organizational architecture. As a result, executives who align business strategy and organizational architecture can consider the impact of the optimization mentioned above on strategy, business goals, objectives, requirements, and projects. The second advantage refers to the impact of the organizational architecture on the strategy. When a domain of the architecture is changed, it can impact the strategy if it is aligned with it $[16,17,20]$. 


\section{Methodology}

This study provides an in-depth case study, regarding business strategy modelling in a company. Thus, the research reported here comes from primary and secondary sources. Semi-structured (formal) interviews, as well as unstructured (informal) conversations, were conducted with the CEO of the company, in order to provide information about the vision and mission of the company, business strategy, main goals, and factors in the internal and external environment of the company that affect its competitive advantage, resources and capabilities, and weaknesses. The CEO was interviewed several times during the research process, and the interactions took place face-to-face on the company's premises. Furthermore, additional details were collected by visiting the company's site [56]. The main steps of the case study are presented as follows:

1. Analysis of the company;

2. Semi-structured (formal) interviews, as well as unstructured (informal) conversations with the CEO of the company;

3. Use of secondary sources for additional information;

4. Identification of the main concepts of business strategy;

5. Recognition of the concepts for designing and modelling ArchiMate;

6. Modelling the company's strategy using ArchiMate;

7. Recommendations for practitioners.

\section{Case Study Description}

The company "XYZ" is a family business, founded in 2018, in Greece. This company operates in the primary sector, specifically in producing and processing dried fruits and beverages. The company's first year was devoted to making and selling dried apples. Then, the company decided to expand into drinks production to secure additional profits. These profits, in correlation with the loan, enabled the company to develop its production line, modernize its machines, and change its physical resources. Furthermore, the company is involved in the production of various types of dried fruits and iced tea.

The company's vision is based on some pillars, the most important of which is its high readability, both nationwide and worldwide. Many activities are being developed right now cannot be considered sustainable. In addition, an interrelated goal of the above is to strengthen all the brand names of the company, as well as their more excellent readability.

The company is currently active in producing beverages (homemade soft drinks and iced tea) that are sold in restaurants. At the same time, it has started making similar drinks under other brand names. In addition, it has a physical store, through which it offers products to consumers. However, the e-shop also plays an important role, through which it offers products to consumers that bear only the brand name of the company. The company's mission is to ensure the smooth operation and viability of all activities undertaken, as well as good cooperation with its partners. Another company's long-term goal is to upgrade its human resources and modernize its manufacturing facilities. The company is currently preparing to hold seminars for this purpose, which it intends to do in the future. The company's main competitive advantage is the development of qualitative products that come from both the raw material and its proper processing during the production process, in combination with the affordable prices that the company has for its products on the market. More specifically, the company guaranteed from the start that it would produce a better product than what was already on the market, while not exceeding the price. Another advantage of the company is that it develops products that concern specific groups of consumers-stores, to meet as many of their needs as possible. Therefore, they can consume, even if it supplies the same quality products, without turning to too many different suppliers.

\section{Results}

The external environmental factors that affect the company, in terms of economy, society, technology, and policy, as well as the actions of the company to address these 
factors, are numerous. Changes in income tax, for example, as well as VAT changes, have a direct impact on the company's movements and strategy. In times of high taxation, the company shifts to the level of investment because it is preferable to invest the income of a higher percentage of the profits, rather than distribute them to the partners and tax them. On the other hand, in times of lower taxation, the company prefers to share profits because the response tax is relatively limited. Another aspect of the economy that directly impacts the company is the development of programs from time to time. The company is constantly pressed to participate in such programs, not only for its development but also to maintain its competitive advantage over other companies that are candidates for participation in these programs.

In terms of society, unemployment and GDP are two variables that define a country's development and, thus, the companies within it. New market trends have always had an impact on society. Therefore, a company is constantly called upon to adapt to these changes. The company continuously develops new products that meet unique needs and penetrates the emerging market sectors. It constantly tries to change its products according to the customers' needs, as the feedback it receives from the consumers plays an essential role in its development.

Regarding the political environment, nowadays, every business is called to harmonize with the political environment and not to work to its detriment. In addition to the many laws that have been enacted in recent years to protect the environment, the company will be conscientious and compliant with the food processing process to achieve the least possible burden.

In recent years, technology has played a significant role in business activities in Greece and worldwide. A considerable influence on the company is the development of food production equipment. The company is constantly striving to evolve and integrate technology into its product line to achieve more outstanding quality and success, while saving money and resources during the manufacturing process. Furthermore, technology has evolved into a powerful media, with the Internet serving as a source of information for new market trends and developments in all business activities. Finally, the company utilizes technology to generate online sales and participate in this new market trend.

However, the company has some weaknesses that must be addressed regularly. The first weakness of the company concerns the lack of liquidity during the winter period because the company is required to produce more than $70 \%$ of the total quantity sold annually, which is intended for the summer period, as the products promoted by the company are preferred in the summer season. To address this weakness, the company has included products sold in winter, so that their profitability ensures liquidity for the production of summer products. Furthermore, a second way to deal with it is to strengthen the company by obtaining working capital from cooperating banks.

The company's second weakness is bureaucracy, which is a significant barrier because it is rapidly growing, forcing it to change its internal environment constantly (e.g., change of space, new facilities, opening new stores, etc.). Thus, the bureaucracy has the effect of delaying the above procedures and, therefore, the company's development. The company addresses this weakness through cooperation with the right people and patience in the given situation.

The third difficulty concerns how the products are distributed nationwide, such as the construction of a product distribution network, because the company is called upon to find many partners, logistics companies, and representatives. Finding new partners, in particular, entails a high margin of risk because the company cannot guarantee immediate and timely payment. Furthermore, in these areas, the company cannot guarantee the high quality of distributions and customer service. As a result, when the company is called upon to expand its network in many areas, it is a significant challenge. To address this challenge, namely network development, choose partners already familiar with the company to increase the chances of a successful collaboration. 
The fourth and last weakness is the existence of marketing by competing companies, as they have existed in the field for several years and, thus, have strengthened their network and brand name towards the consumer. This weakness is addressed through the investment in upgrading the company's brand name because over 50\% of the company's profits are invested in the development of the network and strengthening of its name. More specifically, to strengthen its name, the company sells products not only in various places but also in stores at the beginning of the cooperation, so that they can get the product without investment risk, thus making the product more attractive.

The company's goal is to produce high-quality products and make them available at an affordable price for all consumers. This has been the main goal from its inception, until today. The company tries to adapt quickly to the needs of the market, as well as to get influence from customers to achieve this goal. In addition, a proportion of products are sampled before being placed on the market, in order to ensure consumer approval. However, the company has individual goals. The company's first goal is to expand its human resources and sales network. In addition, the company aims to create stores to sell its products, at least throughout Greece. Another company's goal is to export its products to other countries, both by bringing its brand and by developing products for other companies that will be shipped in turn. Regarding the production sector, the company wishes to enrich it both by including different types of beverages (chocolate, granita, etc.) and enriching the types of existing beverages. Finally, the company aims to launch a complete range of groceries, thus opening a new sales channel.

This company operates in the primary sector, specifically in producing and processing dried fruits and beverages. In order to secure additional profits, the company decided to expand into the production of beverages. Furthermore, the company is involved in the production of various types of dried fruits, as well as iced tea. The company intends to develop a line of products specially designed for sale in a supermarket in the future. The company's vision is to strengthen its brand name and increase sustainability.

Today, the company is mainly engaged in wholesale sales, as well as the supply of restaurants. It also has a retail store, where consumers can purchase the company's products and other similar products. In addition, the company offers its products to its customers through its e-shop. Finally, the company works with other companies to produce products for them under their own brand name. Therefore, the company's mission is to develop high-quality products, derived from both raw material and their proper processing during the manufacturing process, in conjunction with the affordable market-competitive prices. More specifically, the company promised, from the start, that it would produce a better product than what was already on the market, but not at a higher price. Figure 1 presents how both the mission and vision can be modelled.

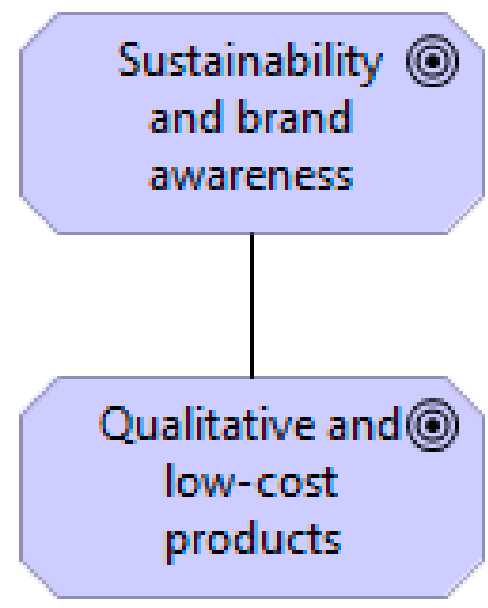

Figure 1. Mission and vision. 
The company operates in an uncertain economic environment, and it is necessary to adapt its operations to economic changes. Tax changes, as well as VAT changes, have a direct impact on the firm's strategy. During periods of high taxation, the company shifts to a higher level of investment because it is preferable to invest the income in a higher percentage of the profits, rather than distribute it to the partners and tax them. On the contrary, the company prefers to share earnings during periods of lower taxation because the corresponding tax is relatively low. Development programs, which occur regularly, are another factor that directly impacts business. The company is constantly urged to participate in such programs, not only for its development but also to maintain its competitive advantage over other companies that are candidates for participation in these programs. Figure 2 presents these different actions that are taken into account by the company, in order to deal with the changes that are caused by the economy.
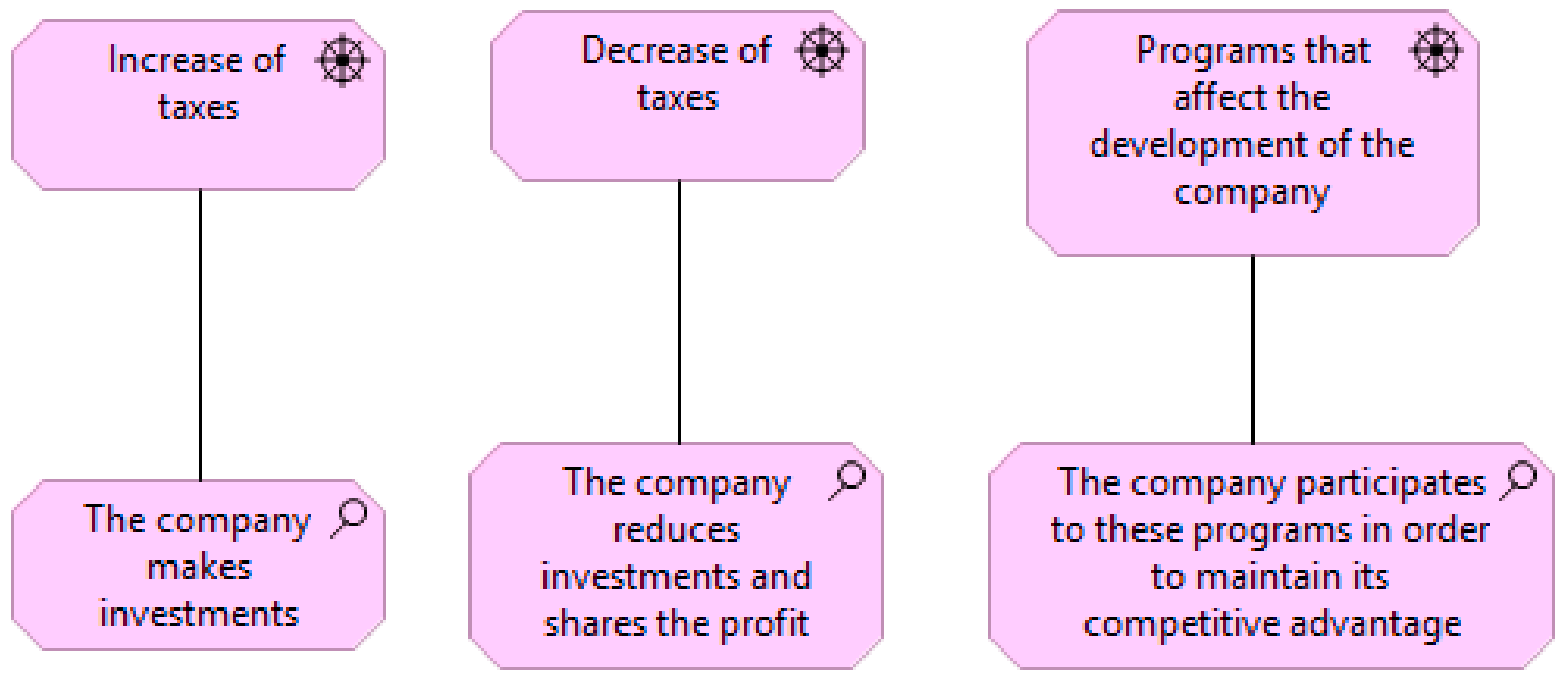

Figure 2. Analysis of external factors-economy.

Other important social factors that affect business operations are unemployment and GDP. Unemployment and GDP are two variables that define development followed by a country and, therefore, the companies within it. New market trends have always had an impact on society. Thus, a company is constantly called upon to adapt to these changes. The company continuously develops new products that meet unique needs and penetrate the emerging market sectors. It constantly tries to change its products, according to the customers' needs, as the feedback it receives from the consumers plays an essential role in its development and consumer behavior changes, based on the resources that are available at any given time. Customers expect new and innovative products, so the company must stay current on new market trends. Figure 3 presents the various actions that the company takes into account, in order to deal with the social changes.

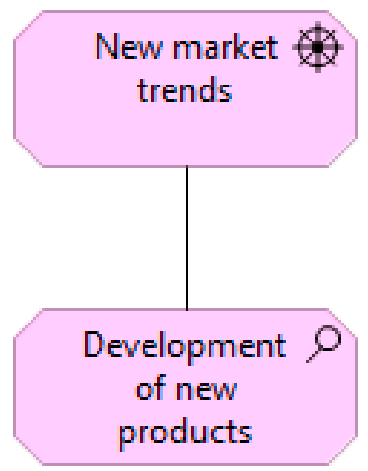

Figure 3. Analysis of external factors and society. 
From a cultural and a political perspective, in addition to the numerous environmental laws that have been enacted in recent years, the company is very careful and compliant with food processing, in order to achieve the lowest possible burden. Figure 4 presents these different actions that are taken into account by the company, in order to deal with the changes that are caused by the political environment.

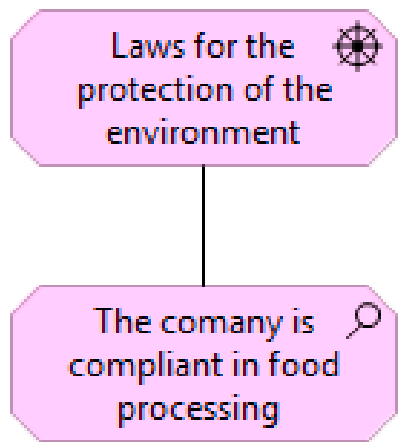

Figure 4. Analysis of external factors and political environment.

The company belongs to a traditional industry and has many competitors. Thus, it is important to provide a variety of products and distribution channels and interact with its customers using new communication channels. Thus, technology is an important factor in the external environment that will support business operations. The development of food production equipment has had a significant impact on the company. The company is constantly striving to evolve and integrate technology into its product line, in order to achieve outstanding quality and success, while saving money and resources during the manufacturing process. Furthermore, technology has evolved into a powerful media, with the Internet serving as a source of information for new market trends and developments in all business activities. Finally, the company utilizes technology to generate online sales and participate in this new market trend. Figure 5 presents the different actions that are taken into account by the company, in order to deal with the changes that are caused by technology.
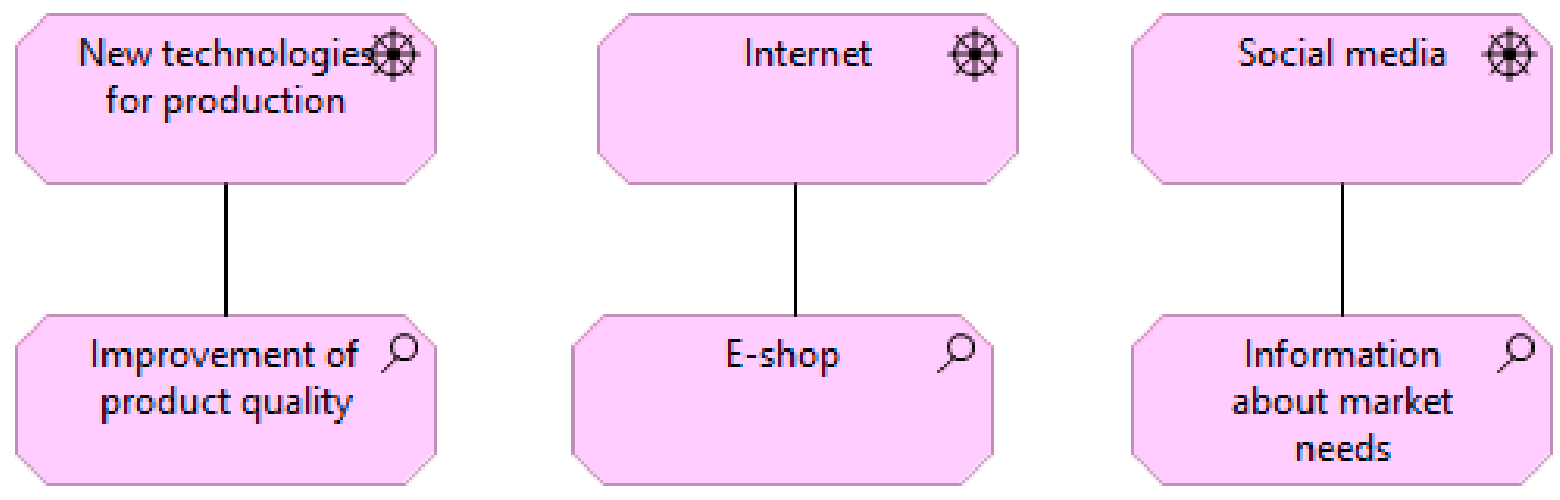

Figure 5. Analysis of external factors and technology.

Despite the changes and pressures for change in the external environment, the company has to take into consideration its resources, in order to improve its weaknesses and increase its competitive advantage. An essential weakness of the company is a lack of liquidity during the winter period because the company must produce more than $70 \%$ of the total quantity sold annually, which is intended for the summer period, as the products promoted by the company are preferred in the summer season. To address this weakness, the company has included products sold in winter, so that their profitability ensures liquidity for the production of summer products. Furthermore, a second way to deal with it is to 
strengthen the company by obtaining working capital from cooperating banks. Figure 6 presents the link between capabilities and external factors.

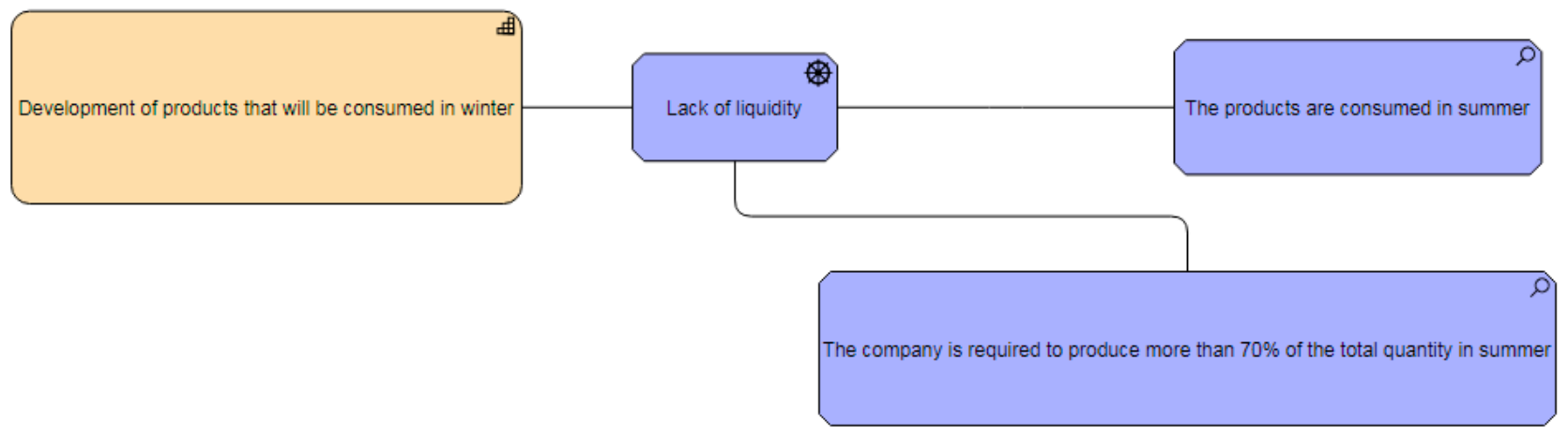

Figure 6. Link between capabilities and external factors.

Another difficulty concerns how the products are distributed nationwide, such as the construction of a product distribution network, because the company is called upon to find many partners, logistics companies, and representatives. Finding new partners, in particular, entails a high margin of risk because the company cannot guarantee immediate and timely payment. As a result, in these areas, the company cannot ensure the high quality of distribution and customer service. As a result, when the company is called upon to expand its network in many areas, it becomes a significant challenge. To address this challenge, namely network development, choose partners already familiar with the company to increase the chances of a successful collaboration. Figure 7 presents the link between capabilities and external factors.

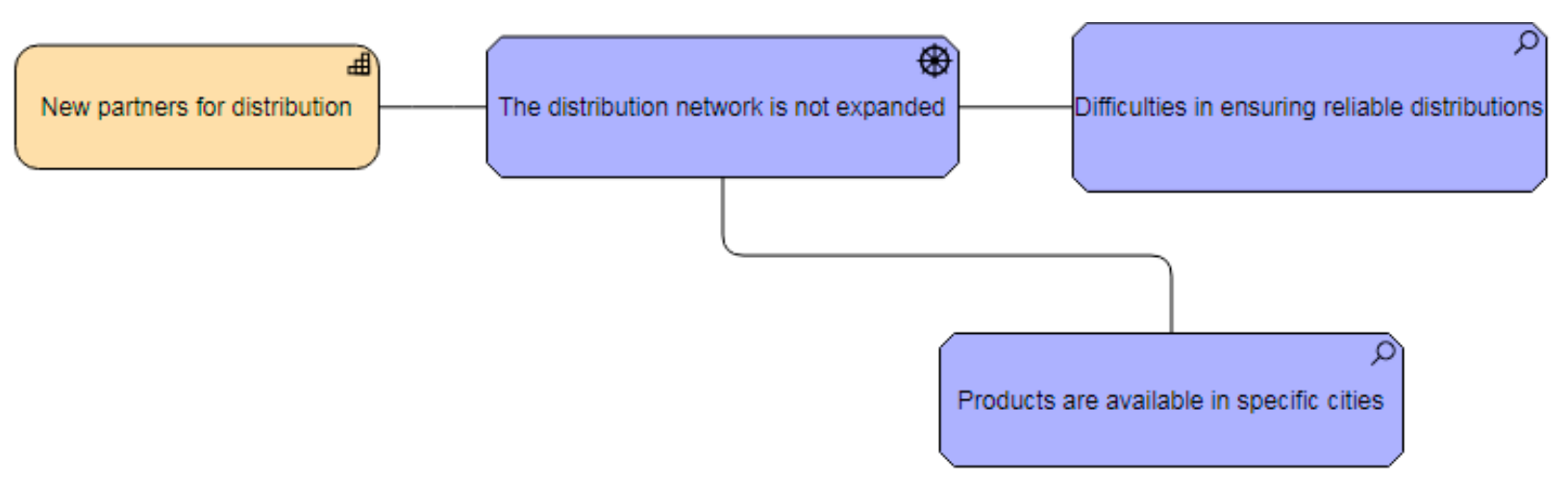

Figure 7. The link between capabilities and external factors.

Finally, another challenge is the existence of marketing by competing companies, as they have existed in the field for several years and, thus, have strengthened their network and brand name towards the consumer. This weakness is addressed through the investment in upgrading the company's brand name because over 50\% of the company's profits are invested in the development of the network and strengthening of its name. More specifically, to strengthen its name, the company sells products not only in various places but also in stores at the beginning of the cooperation to get the product without investment risk, thus making the product more attractive. Figure 8 presents the link between capabilities and external factors.

A company needs to consider which factors, from its internal and external environment, it needs to address and how it wants to formulate a new strategy. In this case, the company formulates a growth strategy to deal with the main challenges that have been described previously. A growth strategy will enable the company to develop new products, expand the distribution channel, and make investments. These activities will help the company deal with the main challenges of the external and internal environment, such 
as the lack of liquidity during the winter period, products that customers do not prefer in the winter, lack of a well-known brand name, bureaucracy, and lack of distribution channels. An essential weakness of the company concerns the lack of liquidity during the winter period. This is because the company must produce more than $70 \%$ of the total quantity sold annually, which is intended for the summer period, as the products produced and promoted by the company are preferred in the summer season. The growth strategy will help the company develop new products, selected by customers, in winter. Figure 9 presents how this strategy can be modelled.

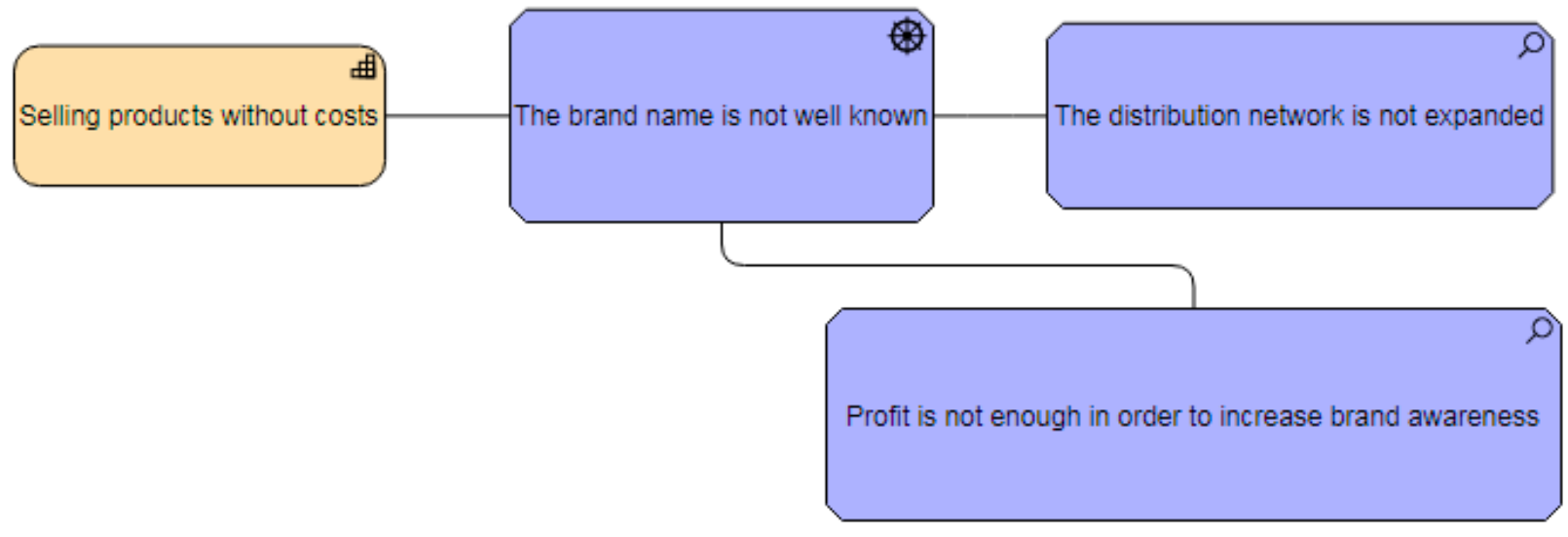

Figure 8. The link between capabilities and external factors.

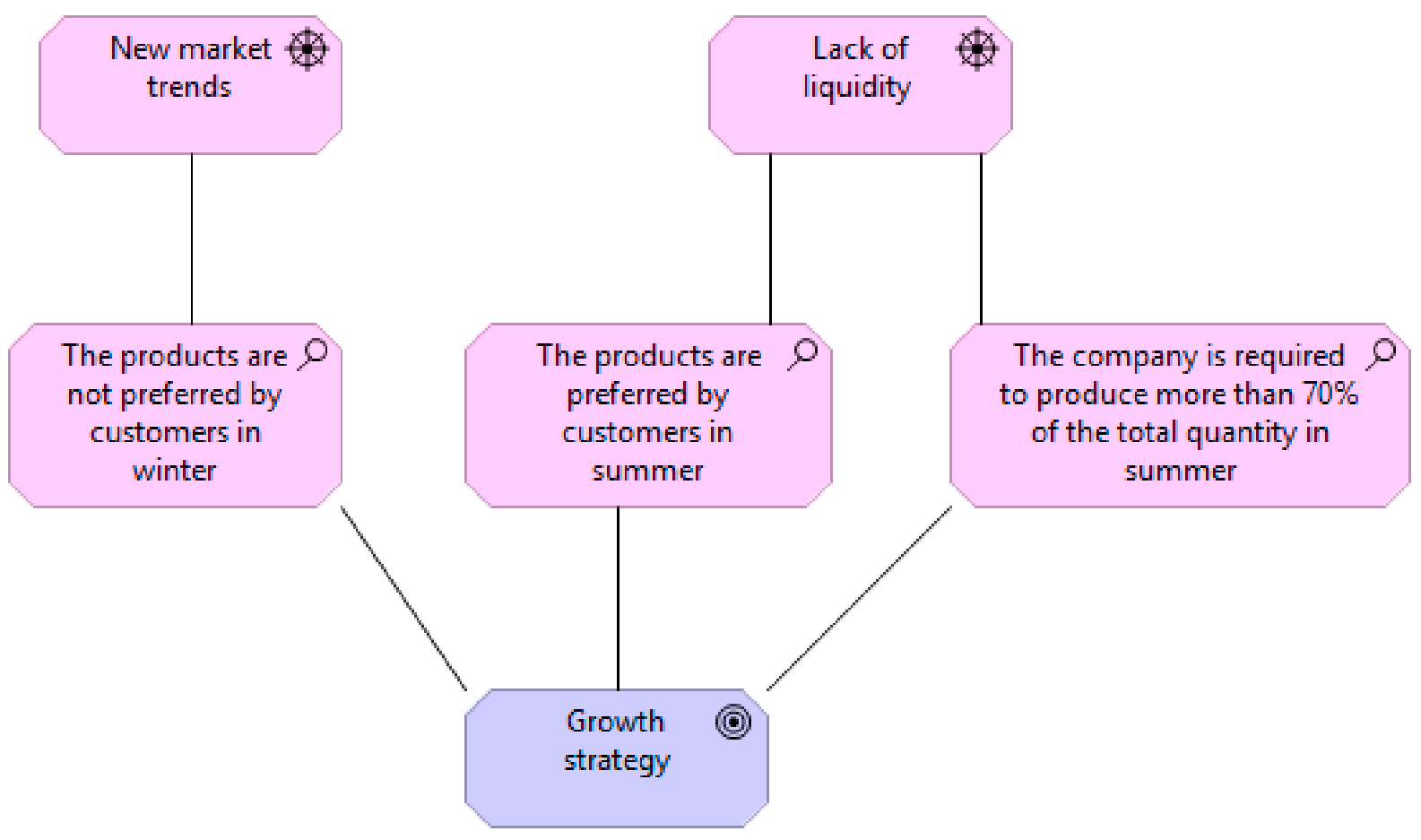

Figure 9. Formulation of the business strategy, based on drivers and assessments.

Another significant weakness is the existence of marketing by competing companies, as they have existed in the field for several years and, thus, have strengthened their network and brand name towards the consumer. This weakness is addressed through the investment in upgrading the company's brand name because over 50\% of the company's profits are invested in the development of the network and strengthening of its name. A growth strategy will help the company make investments to strengthen the brand name. Figure 10 presents how this strategy can be modelled. 


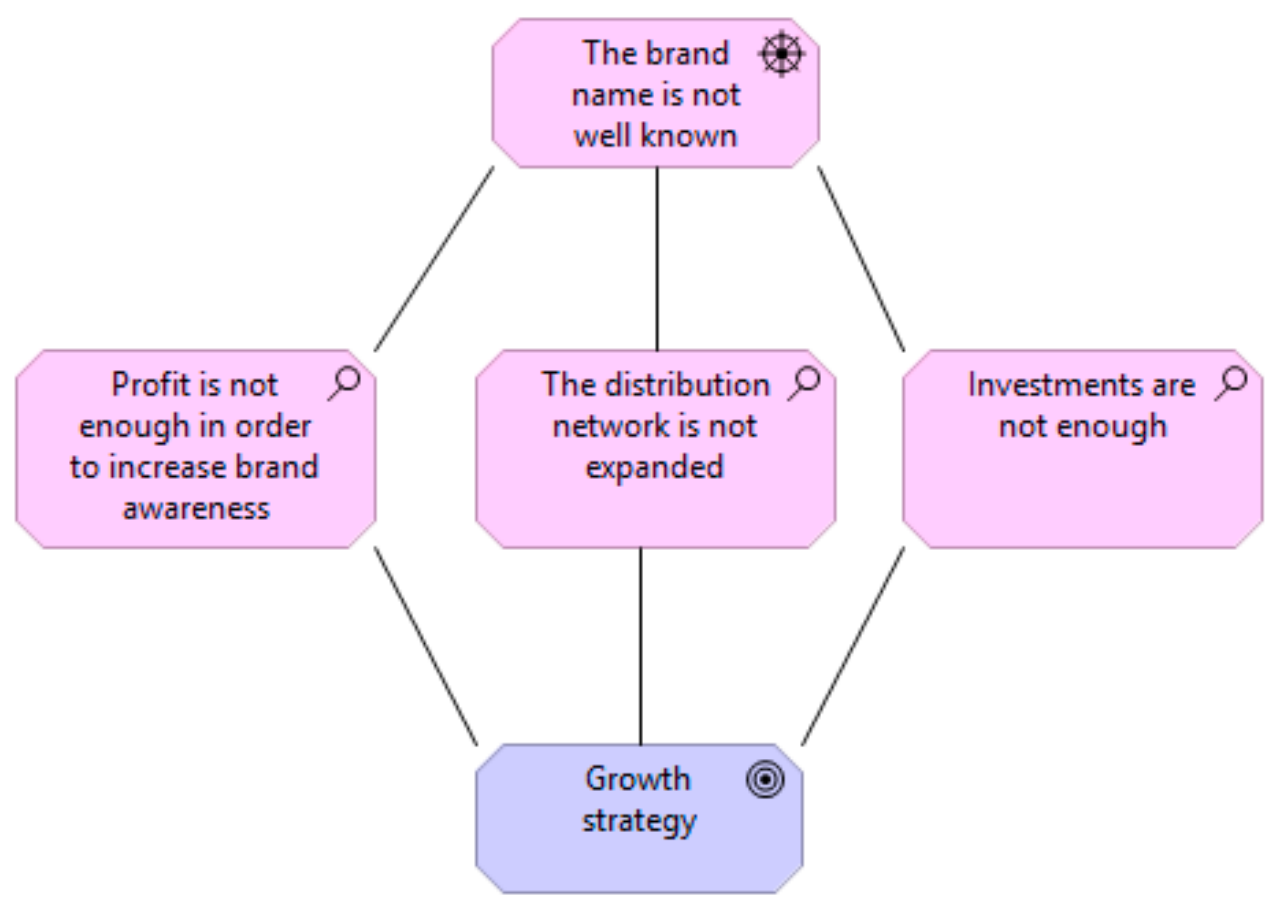

Figure 10. Formulation of the business strategy, based on drivers and assessments.

An essential weakness that the company faces is the bureaucracy, which is a significant barrier for the company because it is rapidly growing, forcing it to constantly change its internal environment (e.g., change of space, new facilities, opening new stores, etc.). Thus, bureaucracy has the effect of delaying the above procedures and, therefore, the company's development. Another difficulty concerns how the products are distributed nationwide, such as the construction of a product distribution network, because the company is called upon to find many partners, logistics companies, and representatives. Finding new partners, in particular, entails a high margin of risk because the company cannot guarantee immediate and timely payment. Furthermore, in these areas, the company cannot ensure the high quality of distributions and customer service. The company's distribution network will be expanded, with the help of a growth strategy. Figure 11 presents how this strategy can be modelled.

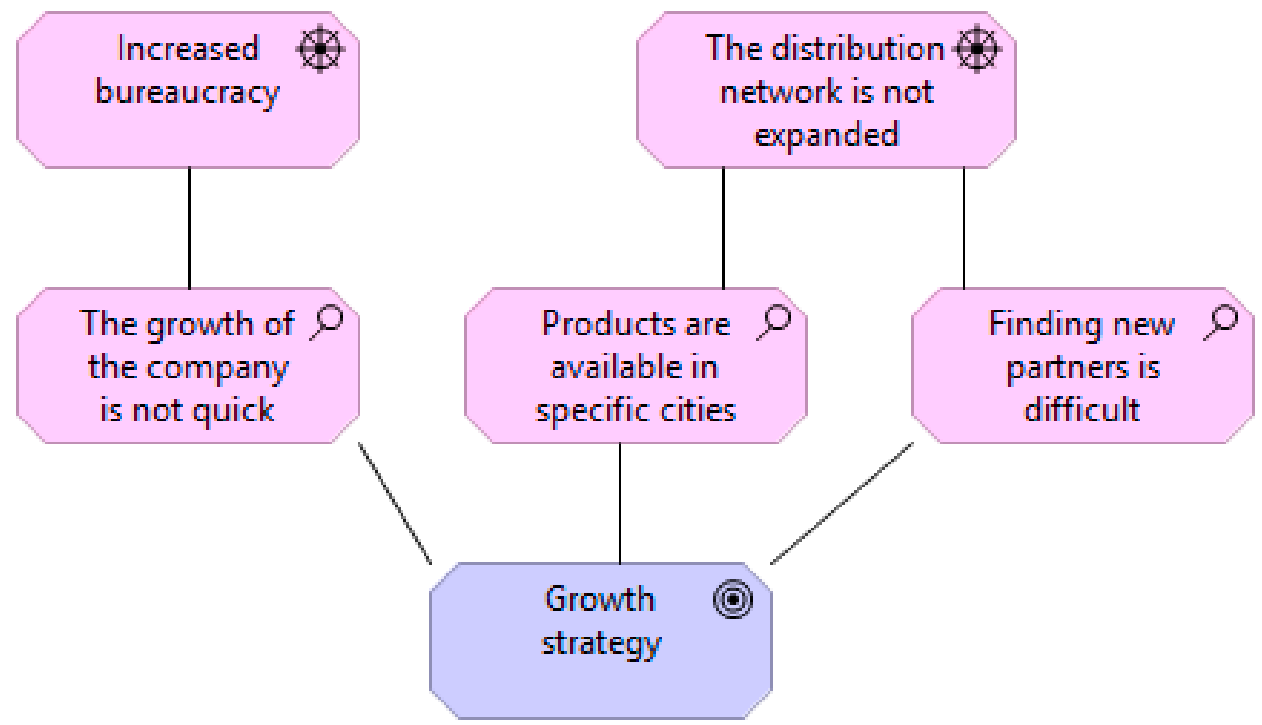

Figure 11. Formulation of the business strategy, based on drivers and assessments. 
The analogy in the way of modelling the goals enables us to identify which are the higher-level (mission, vision), middle-level (strategy), and low-level goals (objectives). Figure 12 presents how these objectives can be modelled. The company sets the following goals to achieve its growth strategy, its overall strategy. For example, it aims to make its production richer by adding a complete grocery line. Furthermore, it intends to increase human resources and, therefore, expand and upgrade the business. Finally, its longterm goal is to create not only a nationwide but a global network, in order to ensure the satisfaction of its customers, since they will have access, wherever they are, to all its products. Therefore, all of the above are related to the business strategy of the company, as well as the mission and vision of the company, which are located at the top of the figure.

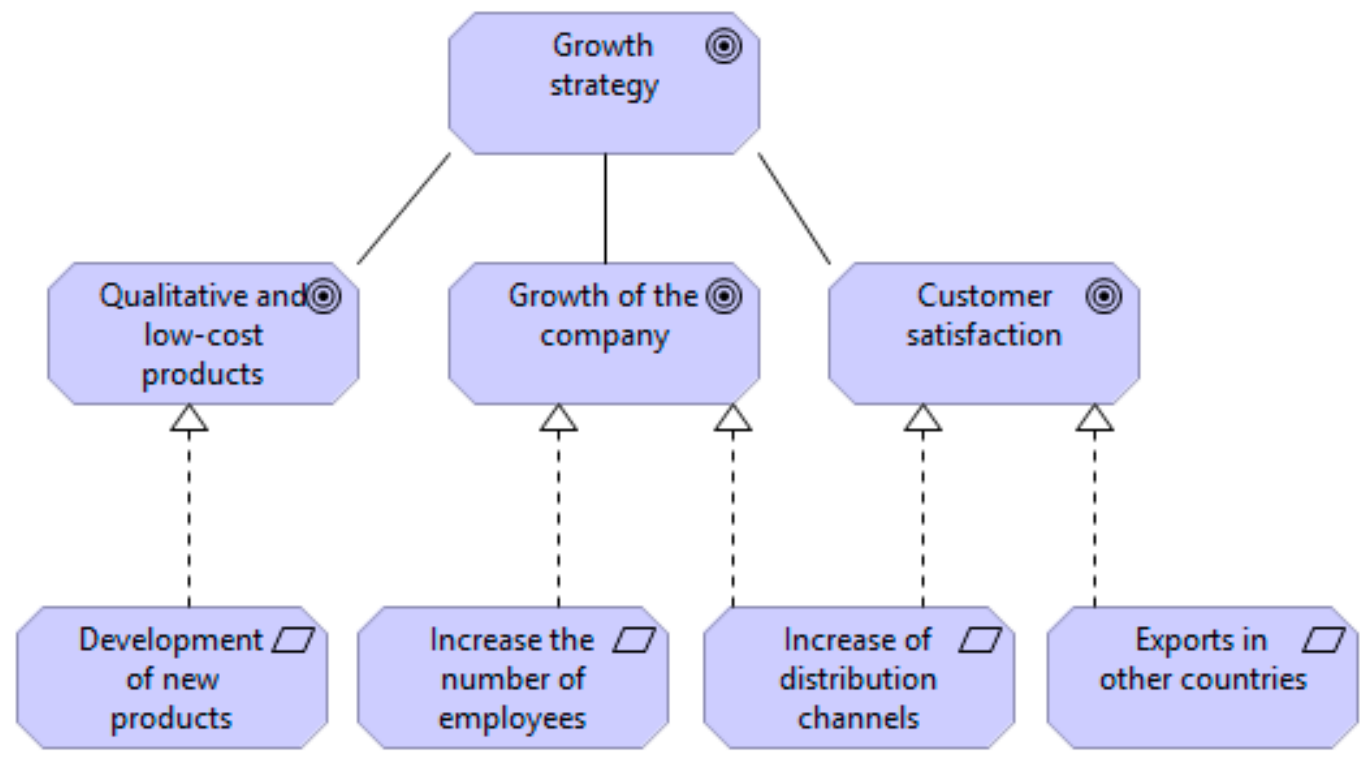

Figure 12. Implementation of a strategy.

Competitors have well-known brand names, but the company should invest more in developing new products to increase brand awareness. Furthermore, a lack of bureaucracy, as well as a distribution channel that has not been expanded, has made it difficult for the company to find new partners, in order to make the products available in more cities and increase profit. To achieve it, a growth strategy can be implemented and help the company implement its mission and vision. The main strategic goals are the production of qualitative products, growth of the company, and satisfaction of customers. The activities that the company will implement to achieve its strategic goals are the development of new products, expansion of distribution channels, exports to other countries, and increase in the number of employees. All the steps of the strategic planning process have been completed and can be modelled together in Figure 13. 


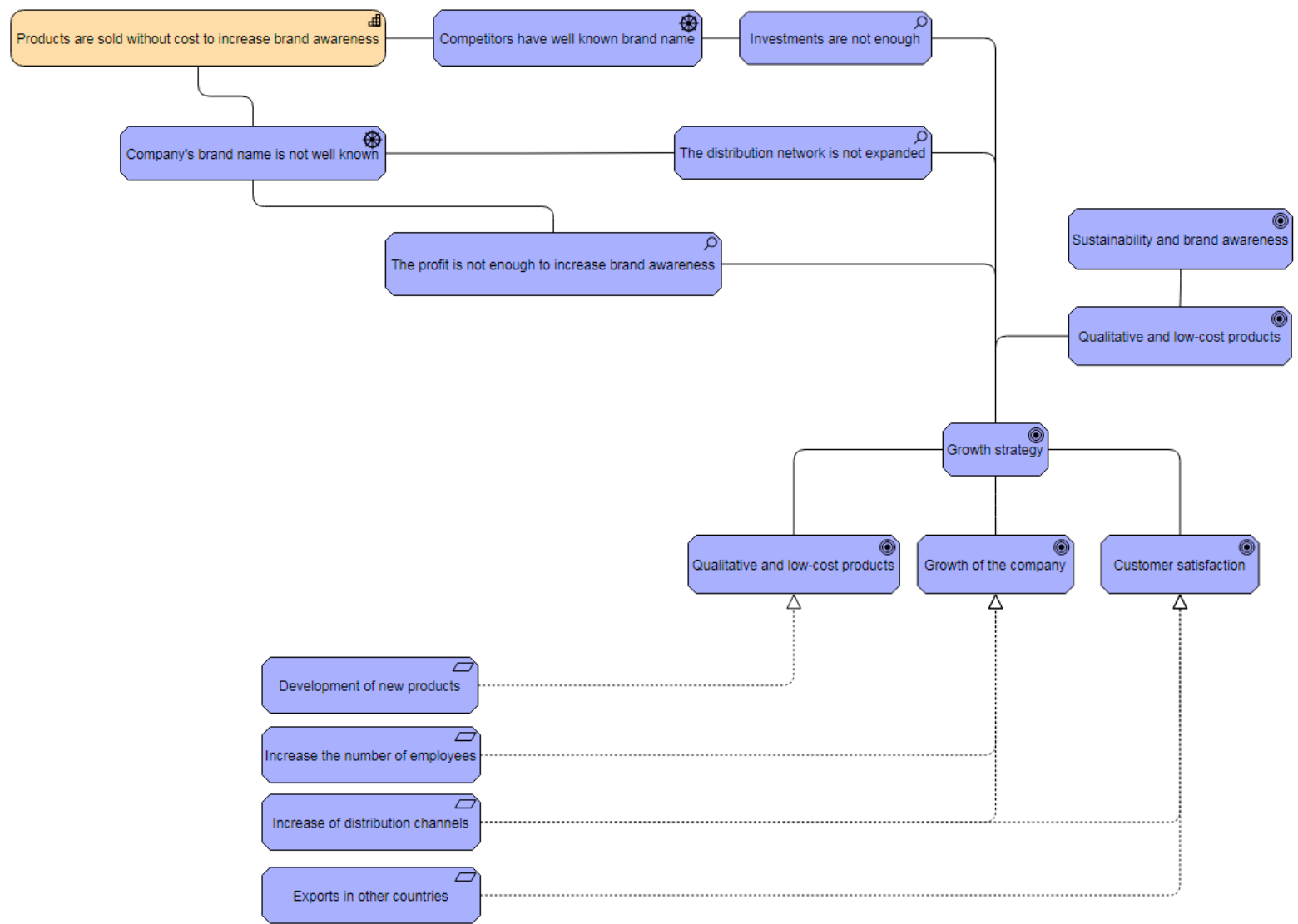

(a)

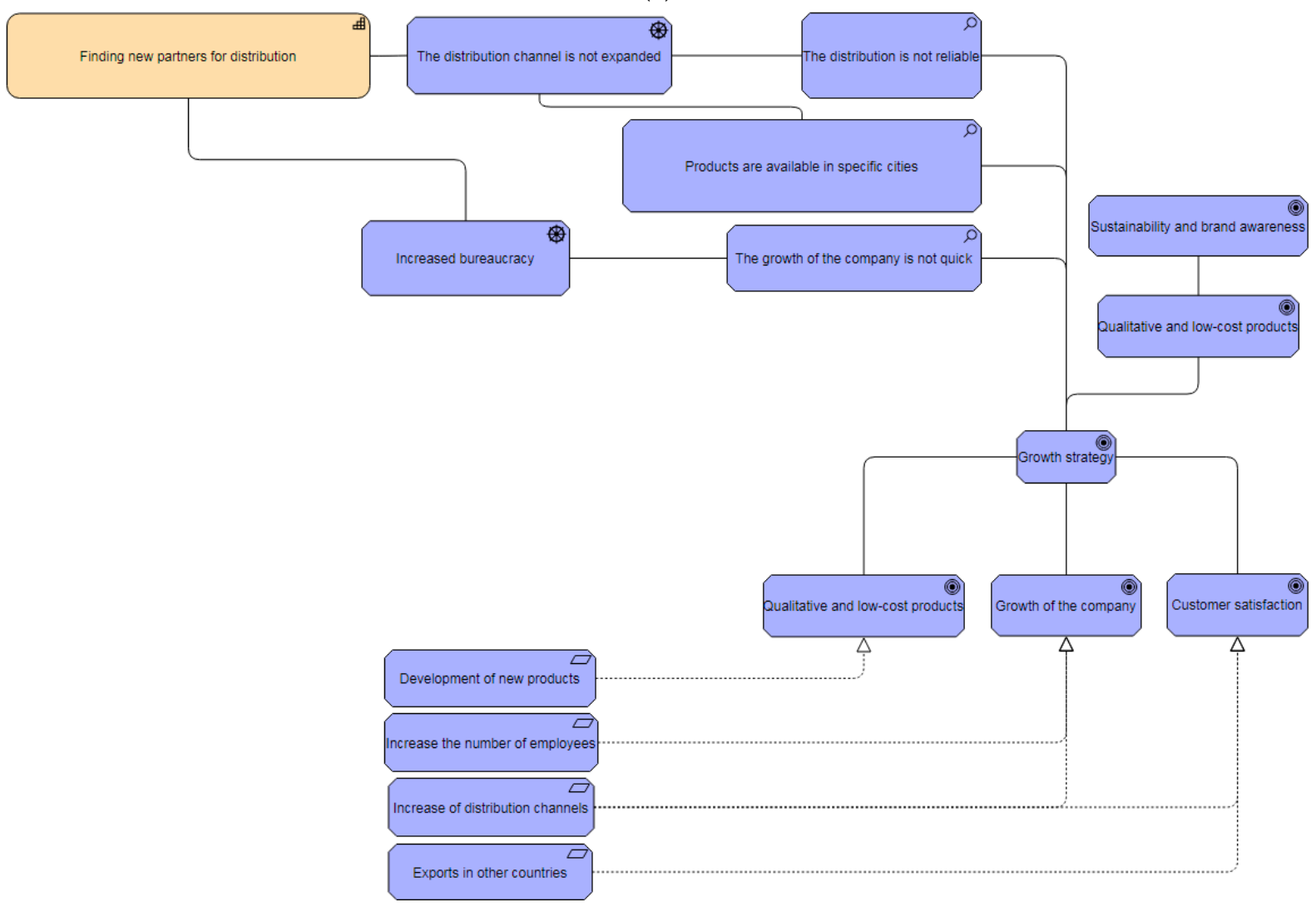

(b)

Figure 13. Cont. 


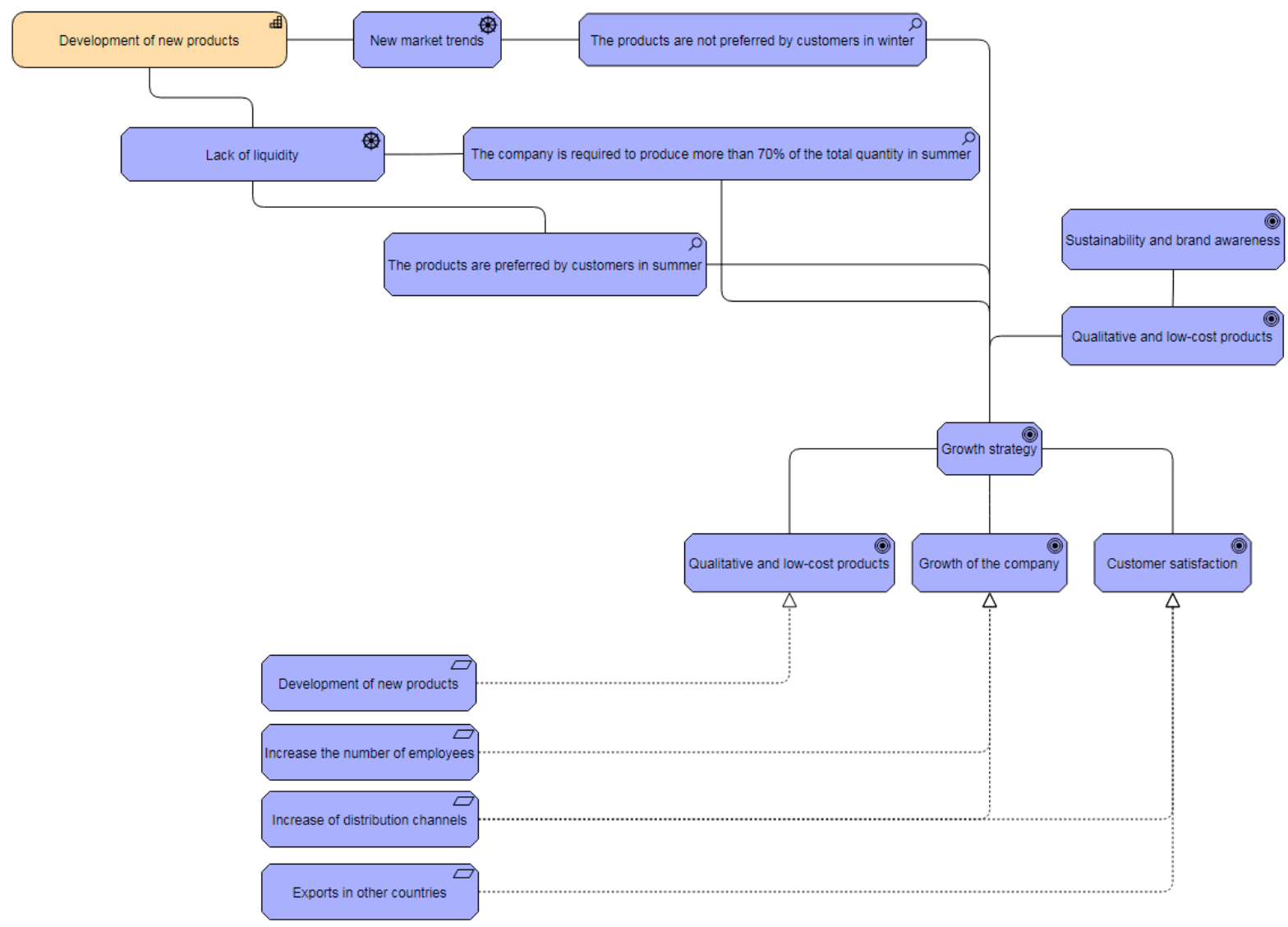

(c)

Figure 13. Modelling the company's holistic strategic planning process (a). Modelling the company's holistic strategic planning process (b). Modelling the company's holistic strategic planning process (c).

\section{Discussion and Recommendations}

The modelling was implemented using particular steps for aligning EA requirements with ArchiMate. The first step was to identify the main concepts of business strategy, and the second step was to determine the concepts for designing and modelling ArchiMate. These steps include the following activities. The first activity was to identify the main concepts of business strategy. The second activity was to determine the required elements of EA and model them with ArchiMate. Specifically, in the first step, the following concepts have been identified: a vision, mission, and business strategy, as well as the capabilities and external factors. The required concepts for designing and modelling ArchiMate were determined in the second step; then, the authors investigated them, as well. To what extent does ArchiMate, as an international EA modelling language, support the above identified concepts to fill the modelling gap? Thus, using this language is an effective way to provide specific steps for business strategy modelling. Furthermore, this language allows the combination of business strategy with other elements of a company (e.g., infrastructure, applications, and business processes). It can be used to present a holistic approach to business modelling.

The company faces many challenges, due to a lack of technical, organizational, and human resources. The specific company tries to digitalize its processes to communicate with their customers, learn about their needs, and develop more qualitative products. The company is constantly striving to evolve and integrate technology into its product line, in order to achieve greater quality success, while saving money and resources during the manufacturing process. Therefore, the modelling of business strategy using ArchiMate supported the company in aligning it with business operations and organizational processes, in order to better understand organizational vision, mission, goals, and culture, as well 
as to increase competitive advantage. Thus, managers can effectively use the company's resources and develop digital tools that help the organization to digitalize its processes and increase its competitive advantage. Without this modelling, managers could not make these decisions, in regard to the use of resources and digital tools, in order to increase business value.

The modelling of company's strategy, using ArchiMate, supported managers in understanding and aligning other elements, such as organizational vision, mission, goals, resources, and capabilities, with competitive advantage. Other frameworks or models, such as $\mathrm{i}^{*}$ framework, KAOS, UEML, and $\mathrm{e}^{3}$-value, focus only on specific concepts, and it would be difficult to align all these concepts with competitive advantage. Therefore, managers could not make decisions about the use of company's resources and digitalization of organizational processes to implement online sales.

This article contributes to the current literature by facilitating knowledge, theories, and ideas from existing research areas, such as strategic planning and EA. Incorporating business strategy into architecture opens new avenues for new possibilities, such as conducting impact analyses of strategy on architecture and changes in architectural technology on strategy.

The modelling takes a more business-oriented approach to EA. This provides integration between the vision of the company and strategic planning process. This paper helps practitioners and EA architects model business strategy using particular steps. This paper presents an avenue to model strategic planning concepts using ArchiMate. Furthermore, by providing information about the strategic planning process, in a structured manner and following explicit mappings to ArchiMate elements, practitioners can facilitate the process. They are combining the concepts of strategic management with EA models. Finally, this approach can help companies with bottom-up decision-making by improving communication between executives and EA architects and making it more interactive.

\section{Conclusions}

In this paper, we have visualized a company's business strategy using ArchiMate. The ArchiMate modelling language was chosen as the basis for this paper because it includes a series of strategy elements that enterprise architects can use to model strategic planning in their firms. Over time, the ArchiMate standard has added many new elements that focus on business strategy, in the form of courses of action, capabilities, and resources. Each of the elements in the language is part of a layer, has a specific notation, and can have many relationships with other elements between and within layers.

A limitation of this paper is that it does not visualize the other layers of the company. Future researchers can use this structure, which is based on the main features of the ArchiMate. There is also the possibility of aligning the strategic with the operational perspective to align the three layers. This supports the development of both a top-down and a bottom-up approach to EA, as well as a perspective focused on organizational and IT aspects. As a result, it aids in aligning the business strategy with IT.

The ArchiMate extensions help researchers ensure a smooth evolution from operational architecture presentations to strategic planning, using basic elements of this modelling language. Moreover, researchers can investigate how advanced analytical elements can be incorporated to implement cross-model analysis and traceability, based on the integrated concepts of strategic management and EA models.

Furthermore, future researchers can conduct interviews with the company to examine how the company has transformed business processes and modelled the "To-Be" strategy. It is essential to bring divergent opinions to a common understanding of business strategy, in order to make the resulting model valuable.

Future researchers could expand on this modelling to support investment decisions, accommodate the identification of business cases for projects, demonstrate projects' contributions to business strategy (portfolio management), and so on. Finally, future action can 
be conducted to develop a meta-model or even an ontology of business strategy planning to model the case study.

Author Contributions: Conceptualization, F.K.; methodology, M.K. (Maria Kamariotou); formal analysis, M.K. (Maria Kyriakopoulou); investigation, M.K. (Maria Kyriakopoulou); data curation, F.K.; writing — original draft preparation, M.K. (Maria Kyriakopoulou) and M.K. (Maria Kamariotou); writing-review and editing, F.K. and M.K. (Maria Kamariotou); visualization, M.K. (Maria Kyriakopoulou); supervision, F.K. All authors have read and agreed to the published version of the manuscript.

Funding: This research received no external funding.

Institutional Review Board Statement: Not applicable.

Informed Consent Statement: Not applicable.

Data Availability Statement: Data sharing not applicable.

Acknowledgments: The authors would like to thank the anonymous reviewers for their valuable comments.

Conflicts of Interest: The authors declare no conflict of interest.

\section{References}

1. Hinkelmann, K.; Pasquini, A. Supporting business and IT alignment by modeling business and IT strategy and its relations to enterprise architecture. In Proceedings of the 2014 Enterprise Systems Conference, Shangai, China, 2-3 August 2014; pp. 149-154.

2. Putro, E.; Hidayanto, A.N.; Prabowo, H. The alignment factors of business-IT on enterprise architecture: A systematic literature review. In Proceedings of the International Conference on Information Management and Technology (ICIMTech), Yogyakarta, Indonesia, 15-17 November 2017; pp. 215-219.

3. Rouhani, B.D.; Mahrin, M.N.R.; Nikpay, F.; Ahmad, R.B.; Nikfard, P. A systematic literature review on Enterprise Architecture Implementation Methodologies. Inf. Softw. Technol. 2015, 62, 1-20. [CrossRef]

4. Šaša, A.; Krisper, M. Enterprise architecture patterns for business process support analysis. J. Syst. Softw. 2011, 84, 1480-1506. [CrossRef]

5. Guillemette, M.G.; Paré, G. Toward a new theory of the contribution of the IT function in organizations. MIS Q. 2012, 36, 529-551. [CrossRef]

6. Baker, J.; Jones, D.; Cao, Q.; Song, J. Conceptualizing the dynamic strategic alignment competency. J. Assoc. Inf. Syst. 2011, 12, 299-322. [CrossRef]

7. Sabegh, M.A.J.; Motlagh, S.M. The Role and Relevance of IT Governance and IT Capability in Business-IT Alignment in Medium and Large Companies. Bus. Manag. Rev. 2012, 2, 16-23.

8. Malta, P.; Sousa, R.D. Process oriented approaches in enterprise architecture for business-IT alignment. Proc. Comput. Sci. 2016, 100, 888-893. [CrossRef]

9. Gerow, J.E.; Grover, V.; Thatcher, J.; Roth, P.L. Looking toward the future of IT-business strategic alignment through the past. MIS Q. 2014, 38, 1159-1186. [CrossRef]

10. Zhang, M.; Chen, H.; Luo, A. A systematic review of business-IT alignment research with enterprise architecture. IEEE Access 2018, 6, 18933-18944. [CrossRef]

11. Saat, J.; Franke, U.; Lagerström, R.; Ekstedt, M. Enterprise architecture meta models for IT/business alignment situations. In Proceedings of the 14th IEEE International Enterprise Distributed Object Computing Conference, Vitória, Brazil, 25-29 October 2010; pp. 14-23.

12. Wegmann, A.; Balabko, P.; Lê, L.S.; Regev, G.; Rychkova, I. A Method and Tool for Business-IT Alignment in Enterprise Architecture. In Proceedings of the CAiSE, Porto, Portugal, 13-17 June 2005; pp. 113-118.

13. Strnadl, C.F. Aligning business and it: The process-driven architecture model. Inf. Syst. Manag. 2006, 23, 67-77. [CrossRef]

14. Choi, J.; Nazareth, D.L.; Jain, H.K. The impact of SOA implementation on IT-business alignment: A system dynamics approach ACM Trans. Manag. Inf. Syst. TMIS 2013, 4, 1-22. [CrossRef]

15. Lederer, M.; Kurz, M.; Lembcke, U. Applying the strategy-oriented business process modeling to S-BPM. In S-BPM ONEApplication Studies and Work in Progress; Zehbold, C., Ed.; Springer International Publishing: Berlin/Heidelberg, Germany, 2014; pp. 67-84.

16. Aldea, A.; Iacob, M.E.; van Hillegersberg, J.; Quartel, D.; Bodenstaff, L.; Franken, H. Modelling strategy with ArchiMate. In Proceedings of the 30th Annual ACM Symposium on Applied Computing, Salamanca, Spain, 13-17 April 2015; pp. $1211-1218$.

17. Aldea, A.; Iacob, M.E.; van Hillegersberg, J.; Quartel, D.; Franken, H. Modelling value with archimate. In Advanced Information Systems Engineering Workshops; Persson, A., Stirna, J., Eds.; Springer International Publishing: Berlin/Heidelberg, Germany, 2015; pp. 375-388. 
18. Aldea, A.; Iacob, M.E.; Quartel, D.; Franken, H. Strategic planning and enterprise achitecture. In Proceedings of the First International Conference on Enterprise Systems: ES 2013, Cape Town, South Africa, 7-8 November 2013; pp. 1-8.

19. Aldea, A.; Iacob, M.E.; van Hillegersberg, J.; Quartel, D.; Franken, H. Strategy on a Page: An ArchiMate-based tool for visualizing and designing strategy. Intell. Syst. Account. Financ. Manag. 2018, 25, 86-102. [CrossRef]

20. Kitsios, F.; Kamariotou, M. Business strategy modelling based on enterprise architecture: A state of the art review. Bus. Process Manag. J. 2019, 25, 606-624. [CrossRef]

21. Kitsios, F.; Kamariotou, M. Enterprise Architecture Management for Business Strategy Modelling. In Proceedings of the BAM 2017 Conference, Coventry, UK, 4-7 September 2017; pp. 1-24.

22. Kamariotou, M.; Kitsios, F. Evaluating IT alignment and performance in SMEs using Multivariate Regression Analysis. In Proceedings of the 19th International Conference on Electronic Business (ICEB), Newcastle, UK, 8-12 December 2019; pp. 222-230.

23. Kitsios, F.; Kamariotou, M. Information Systems Strategy and Innovation: Analyzing perceptions using MCDA. IEEE Trans. Eng. Manag. 2021. [CrossRef]

24. Kitsios, F.; Kamariotou, M. Information Systems Strategy and Strategy-as-Practice: Planning Evaluation in SMEs. In Proceedings of the Americas Conference on Information Systems (AMCIS), Cancun, Mexico, 15-17 August 2019; pp. 1-10.

25. Kitsios, F.; Kamariotou, M. Strategic IT Alignment and Business Performance in SMEs: An Empirical Investigation. In Business Information Systems Workshops, Springer LNBIP 373; Abramowicz, W., Corchuelo, R., Eds.; Springer: Berlin/Heidelberg, Germany, 2019; pp. 113-123.

26. Kitsios, F.; Kamariotou, M. Strategizing Information Systems: An empirical analysis of IT Alignment and Success in SMEs. Computers 2019, 8, 74. [CrossRef]

27. Kitsios, F.; Kamariotou, M. Strategic IT alignment: Business performance during financial crisis. In Advances in Applied Economic Research, Springer Proceedings in Business and Economics; Tsounis, N., Vlachvei, A., Eds.; Springer: Berlin/Heidelberg, Germany, 2017; pp. 503-525.

28. Ilmudeen, A.; Bao, Y.; Alharbi, I.M. How does business-IT strategic alignment dimension impact on organizational performance measures. J. Enterp. Inf. Manag. 2019, 32, 457-476. [CrossRef]

29. Sabherwal, R.; Sabherwal, S.; Havakhor, T.; Steelman, Z. How does strategic alignment affect firm performance? The roles of information technology investment and environmental uncertainty. MIS Q. 2019, 43, 453-474. [CrossRef]

30. Balhareth, $\mathrm{H}$. The relationship between business-IT alignment and organisational performance: An empirical investigation from multilevel view. Int. J. Bus. Inf. Syst. 2018, 29, 421-435.

31. Canhoto, A.I.; Quinton, S.; Pera, R.; Molinillo, S.; Simkin, L. Digital strategy aligning in SMEs: A dynamic capabilities perspective. J. Strateg. Inf. Syst. 2021, 30, 101682. [CrossRef]

32. Hill, C.W.; Jones, G.R. Strategic Management: An Integrated Approach; Cengage Learning: Boston, MA, USA, 2008.

33. Wolf, C.; Floyd, S.W. Strategic planning research: Toward a theory-driven agenda. J. Manag. 2017, 43, 1754-1788. [CrossRef]

34. Zakrzewska-Bielawska, A. Perceived mutual impact of strategy and organizational structure: Findings from the high-technology enterprises. J. Manag. Organ. 2016, 22, 599-622. [CrossRef]

35. Zakrzewska-Bielawska, A. The relationship between managers' network awareness and the relational strategic orientation of their firms: Findings from interviews with polish managers. Sustainability 2018, 10, 2691. [CrossRef]

36. Johnson, G.; Scholes, K.; Whittington, R. Exploring Corporate Strategy: Text E Cases, 8th ed.; Prentice Hall: Hoboken, NJ, USA, 2008.

37. Bleistein, S.J.; Cox, K.; Verner, J. Validating strategic alignment of organizational IT requirements using goal modeling and problem diagrams. J. Syst. Softw. 2006, 79, 362-378. [CrossRef]

38. Iacob, M.E.; Quartel, D.; Jonkers, H. Capturing business strategy and value in enterprise architecture to support portfolio valuation. In Proceedings of the 16th International on Enterprise Distributed Object Computing Conference (EDOC), Beijing, China, 10-14 September 2012; pp. 11-20.

39. Azevedo, C.L.; Almeida, J.P.A.; van Sinderen, M.; Pires, L.F. Towards capturing strategic planning in EA. In Proceedings of the 19th International Conference on Enterprise Distributed Object Computing (EDOC), Adelaide, SA, Australia, 21-25 September 2015; pp. 159-168.

40. Giannoulis, C.; Petit, M.; Zdravkovic, J. Modeling competition-driven business strategy for business IT alignment. In Advanced Information Systems Engineering Workshops; Salinesi, C., Pastor, O., Eds.; Springer: Berlin/Heidelberg, Germany, 2011 ; pp. 16-28.

41. Giannoulis, C.; Petit, M.; Zdravkovic, J. Modeling business strategy: A meta-model of strategy maps and balanced scorecards. In Proceedings of the 5th International Conference on Research Challenges in Information Science (RCIS), Gosier, Guadeloupe, France, 11-14 May 2011; pp. 1-6.

42. Giannoulis, C.; Zdravkovic, J.; Petit, M. Model-centric strategy-IT alignment: An empirical study in progress. In Advanced Information Systems Engineering Workshops; Franch, X., Soffe, P., Eds.; Springer: Berlin/Heidelberg, Germany, 2013 ; pp. 146-155.

43. Azevedo, C.L.; Iacob, M.E.; Almeida, J.P.A.; van Sinderen, M.; Pires, L.F.; Guizzardi, G. Modeling resources and capabilities in enterprise architecture: A well-founded ontology-based proposal for ArchiMate. Inf. Syst. 2015, 54, 235-262. [CrossRef]

44. Yamamoto, S.; Morisaki, S. IT Demand Governance using Business Goal Structuring Notation. In Proceedings of the 6th International Conference on IT Convergence and Security (ICITCS), Prague, Czech Republic, 26-29 September 2016; pp. 1-5.

45. Svee, E.O.; Giannoulis, C.; Zdravkovic, J. Modeling business strategy: A consumer value perspective. In The Practice of Enterprise Modeling. PoEM 2011; Johannesson, P., Krogstie, J., Opdahl, A.L., Eds.; Springer: Berlin/Heidelberg, Germany, 2011 ; pp. 67-81. 
46. Stanisławski, R. Open innovation as a value chain for small and medium-sized enterprises: Determinants of the use of open innovation. Sustainability 2020, 12, 3290. [CrossRef]

47. Stanisławski, R. Determinants of innovative development and their importance for small and medium-sized enterprises in Poland. Int. J. Innov. Learn. 2021, 29, 67-88. [CrossRef]

48. Kitsios, F.; Athanasiou, S.; Kamariotou, M. Mapping Business Model Using Archimate: The case of Open Data Ecosystem. In Proceedings of the XIV Balkan Conference on Operational Research (Virtual BALCOR 2020), Thessaloniki, Greece, 30 September-3 October 2020; pp. 340-344.

49. Velitchkov, I. Integration of IT strategy and enterprise architecture models. In Proceedings of the 9th International Conference on Computer Systems and Technologies and Workshop for PhD Students in Computing, Gabrovo, Bulgaria, 12-13 June 2008; pp. 69-74.

50. Doumi, K.; Baïna, S.; Baïna, K. Experimenting a Modeling Approach for Modeling Enterprise Strategy in the Context of Strategic Alignment. In Enterprise Information Systems; Cruz-Cunha, M.M., Varajão, J., Powell, P., Martinho, R., Eds.; Springer: Berlin/Heidelberg, Germany, 2011; pp. 356-368.

51. Zarzewska-Bielawska, A. The strategic dilemmas of innovative enterprises: Proposals for high-technology sectors. RED Manag. 2012, 42, 303-314.

52. Lee, H.; Song, Y.T. Bridging enterprise architecture requirements to archimate. In Computers, Networks, Systems, and Industrial Engineering 2011; Lee, R., Ed.; Springer: Berlin/Heidelberg, Germany, 2011; pp. 63-78.

53. Girsang, A.S.; Abimanyu, A. Development of an Enterprise Architecture for Healthcare using TOGAF ADM. Emerg. Sci. J. 2021, 5, 305-321. [CrossRef]

54. Puspitasari, I. Extending IT-based Competitive Strategy Framework using Architecture Vision and Business Architecture of TOGAF Architecture Development Method (ADM). In Proceedings of the 9th International Conference on Information Communication and Management, New York, NY, USA, 23-26 August 2019; pp. 37-42.

55. Nisaa'Andi, S.T.; Amalia, N.A.; Lubis, M. IT Roadmap to Improve Business Strategy using TOGAF ADM: A Case Study of Government-Owned Electricity Company. J. Phys. Conf. Ser. 2019, 1361, 012017. [CrossRef]

56. Anggraini, N.; Legowo, N. Cloud Computing Adoption Strategic Planning Using ROCCA and TOGAF 9.2: A Study in Government Agency. Proc. Comput. Sci. 2019, 161, 1316-1324. [CrossRef]

57. Danesh, M.H.; Yu, E. Towards a Framework for Shaping \& Forming Enterprise Capabilities. In The Practice of Enterprise Modeling. PoEM 2018. Lecture Notes in Business Information Processing; Buchmann, R., Karagiannis, D., Kirikova, M., Eds.; Springer: Cham, Switzerland, 2018; pp. 188-202.

58. Danesh, M.H.; Yu, E. Modeling enterprise capabilities with I*: Reasoning on alternatives. In CAiSE 2014 Workshops, Lecture Notes in Business Information Processing; Iliadis, L., Papazoglou, M., Pohl, K., Eds.; Springer International Publishing: Cham, Switzerland, 2014; pp. 112-123.

59. Sandkuhl, K.; Stirna, J.; Holz, F. Modeling Products and Services with Enterprise Models. In The Practice of Enterprise Modeling. PoEM 2020. Lecture Notes in Business Information Processing; Grabis, J., Bork, D., Eds.; Springer: Cham, Switzerland, 2020; pp. 41-57.

60. Sandkuhl, K.; Stirna, J.; Persson, A.; Wißotzki, M. Enterprise Modeling. Taking Business Challenges with the 4EM Method; Springer: Berlin/Heidelberg, Germany, 2014; Chapter 14; pp. 233-272.

61. Caetano, A.; Antunes, G.; Bakhshandeh, M.; Borbinha, J.; Da Silva, M.M. Analysis of federated business models: An application to the business model canvas, ArchiMate, and e3value. In Proceedings of the 17th Conference on Business Informatics, Lisbon, Portugal, 13-16 July 2015; pp. 1-8.

62. Lucas, H.C., Jr.; Goh, J.M. Disruptive technology: How Kodak missed the digital photography revolution. J. Strateg. Inf. Syst. 2009, 18, 46-55. [CrossRef]

63. Meertens, L.O.; Iacob, M.E.; Nieuwenhuis, L.J.; van Sinderen, M.J.; Jonkers, H.; Quartel, D. Mapping the business model canvas to ArchiMate. In Proceedings of the 27th Annual ACM Symposium on Applied Computing, Trento, Italy, 26-30 March 2012; pp. 1694-1701.

64. Archi Archimate Modelling. Available online: https://www.archimatetool.com/ (accessed on 19 August 2021).

65. Iacob, M.E.; Meertens, L.O.; Jonkers, H.; Quartel, D.A.; Nieuwenhuis, L.J.; Van Sinderen, M.J. From enterprise architecture to business models and back. Softw. Syst. Modeling 2014, 13, 1059-1083. [CrossRef]

66. Fritscher, B.; Pigneur, Y. Business IT alignment from business model to enterprise architecture. In Advanced Information Systems Engineering Workshops; Salinesi, C., Pastor, O., Eds.; Springer: Berlin/Heidelberg, Germany, 2011; pp. 4-15. 